\title{
What Drives Streamers? Users' Characteristics and Motivations on Social Live Streaming Services
}

\author{
Franziska Zimmer \\ Heinrich Heine University \\ Düsseldorf, Germany \\ franziska.zimmer@hhu.de
}

\author{
Katrin Scheibe \\ Heinrich Heine University \\ Düsseldorf, Germany \\ katrin.scheibe@hhu.de
}

\begin{abstract}
With platforms such as YouNow, Periscope and Ustream, a new type of social networking services (SNSs) became popular, namely general social live streaming services (SLSSs). SLSSs combine Live-TV and social media, leading to video-based social computing. In the empi rical part of the paper, we are going to answer three research questions: (1) What are the motivations of the streamers? (2) Is there a relation between motivations and streamed contents? (3) Do gender-specific and generational differences in motivation exist? As research methods, we worked with the systematic observations and content analysis of live online videos $(N=7,667)$.
\end{abstract}

\section{Introduction}

Social live streaming services (SLSSs) such as Periscope $^{1}$, Ustream ${ }^{2}$, YouNow ${ }^{3}$, Facebook Live ${ }^{4}$, niconico ${ }^{5}$ (in Japan), $\mathrm{QQ}^{6}$, Panda ${ }^{7}$ (both in China) or - for broadcasting e-sports resp. drawing - Twitch ${ }^{8}$ and Picarto $^{9}$ (Table 1) are social media, which combine Live Streaming with elements of Social Networking Services (SNSs) including a backchannel from the viewer to the streamer and among the viewers. SLSSs allow their users to broadcast their online videos to everyone who wants to watch, all over the world. The streamers film either with the camera of a mobile phone or with the aid of a webcam. The viewers are able to search for ongoing

\footnotetext{
${ }^{1}$ https://www.pscp.tv/

2 http://video.ibm.com/

${ }^{3}$ https://www.younow.com/

${ }^{4}$ https://live.fb.com/

${ }^{5}$ http://www.nicovideo.jp/

${ }^{6}$ https://live.qq.com/

${ }^{7}$ https://www.panda.tv/

${ }^{8}$ https://www.twitch.tv/

${ }^{9}$ https://picarto.tv/
}

streams (1) with streaming locations on a world map (as offered by Periscope) or with hashtags (as pull services) and (2) as the streamers distribute information on their upcoming streams to potential viewers via the SLSS and multiple other social media channels (as a push service).

Table 1. Global and country-specific ranks of SLSS websites

\begin{tabular}{lcc}
\hline SLSS & Global Rank & $\begin{array}{c}\text { Rank in Top } \\
\text { Country }\end{array}$ \\
\hline YouTube* & 2 & U.S.: 2 \\
Facebook** & 3 & U.S.: 4 \\
QQ** & 8 & CN: 2 \\
Twitch & 33 & U.S.: 14 \\
niconico* & 110 & JP: 9 \\
Bilibili & 212 & CN: 32 \\
Panda & 1,751 & CN: 117 \\
Periscope & 2,916 & U.S.: 1,620 \\
YY** & 4,234 & CN: 474 \\
Long Zhu & 6,413 & CN: 662 \\
Ustream & 8,470 & U.S.: 4,675 \\
Qiuxiu (x.pps.tv) & 8,684 & CN: 1,137 \\
YouNow & 9,125 & U.S.: 7,037 \\
Kuaishou** & 10,267 & CN: 1,400 \\
Picarto & 10,660 & U.S.: 3,911 \\
\hline
\end{tabular}

Data source: Alexa (as of June 11, 2018); *: SLSS

and video sharing; **: SLSS and asynchronous

Social Networking Service

SLSSs are not only one of the latest social media; research on SLSSs is on its infancy. One of the first services was launched in 2007, namely Livestream.com ${ }^{10}$. Therefore, this research topic is only expanding since the last few years. There is a practical guide to create live streams [1]. SLSSs find application in private contexts [2], but also in serious environments, e.g. in teaching neurosurgery [3] or economics [4]. There are first thoughts on applying

${ }^{10}$ https://livestream.com/about 
SLSSs in marketing [5]. These services see also use in live broadcasting sports events; however, there are massive legal problems [6]. Authors have discussed legal and ethical implications of SLSSs [7-9], while others focus on privacy [10]. If we differentiate between topic-specific SLSSs (as Twitch or Picarto) and general SLSSs (without any thematic limitation) [2], we are able to identify some scientific studies on specific SLSSs, especially Twitch [e.g., 11-16], and a few on general SLSSs, especially on Periscope, YouNow and Ustream [2, 17-26]. Studies found that general live streaming was appreciated for its authentic, unstrained, and interactive attributes [17] as well as for its role for sharing breaking news [18].

Membership, emotional connection, and influence of the users' sense of virtual community in live streaming affect the purchase intention on of the users on SLSSs [27]. Concerning the gender of the streamers, a study showed that there are significant differences based on whether a viewer of a live broadcast is watching the same or different gender and whether someone wants to interact with the livevideo content [28].

Chen and Lin [29] investigated the aspects of entertainment and social interaction and their relationship with attitude, perceived value and watching intention to understand the influential factors and channels that induce the audience to watch live streaming events. Zhao et al. [30] studied Twitch streamers' motives in accordance with the self-determination theory.

However, we miss studies which investigate SLSSs' users' motivations to stream, their gender and age, and the content of the streams. The aim of this article is to close those research gaps.

Why do users apply an SLSS and produce content? Based on the Uses and Gratifications approach of Blumler and Katz [31], the use of media is guided by the fulfillment of certain needs and the search for reward and satisfaction of expectations. McQuail [32] has summarized four central motives for the use of media, namely entertainment, information, self-presentation, and social interaction. According to further research about user behavior on SLSSs [33] we should talk about self-presentation instead of self-realization. Furthermore, users on SNSs may be divided into three different groups producers, consumers as well as participants, whereas each group is driven by different motives [34]. Following Shao [34], the motives of consumers are information and entertainment. For participants, additionally, it is social interaction and finally, for producers - the group this investigation is about - all four motives apply [33,35].
In the empirical part of the paper, we turn to general SLSSs (YouNow, Periscope, and Ustream) and are going to answer three research questions:

RQ1: What are the motivations of the streamers?

RQ2: Are there differences in user-generated content between users driven by different motivations to stream?

RQ3: Are there any gender-specific or generation-al-dependent differences in streamers' motivations?

\section{Methods}

Apart from surveys, interviews, and experiments in controlled situations, we are able to use two different sources for data gathering on SLSSs, namely log-files of the information systems, and systematic observations of the online videos. As logfiles' data are not very meaningful (it is impossible to get data on users' motives and streams' content) we can only use this source for some basic data as, for instance, for describing some user characteristics (e.g., country of dial-up) and interaction data (e.g., time on the SLSS) [36]. We realized systematic observations of the live streams. The analysis of logfiles is not sufficient for analyzing the content of a stream and therefore a content analysis was chosen to gain insight into the produced content on SLSSs. The information converted from the content is valuable for businesses, since social media is considered as a marketing platform [37]. Analyzing the motives of generations and genders is crucial since people use social media differently depending on their age and gender. Studies show that generations as well as male and female users have different motivations to apply social media [38,39], so the research should be expanded on to SLSSs as well. Since the users exhibit different motives, the investigation on what motives they explicitly have to use SLSSs should be conducted as well.

For our investigation, a team of researchers assessed, evaluated and compared SLSSs' users' streaming behavior as well as the content of a stream and motives of a streamer to produce a live stream $[9,19]$. Each stream was chosen at random on the platform's homepage by the researcher. No stream was favored over another and no personal preferences influenced the randomization process. The empirical procedure of content analysis [37,40,41] was implemented as follows. A codebook was developed. Two different approaches [42] were applied to get the content categories as well as motives and to ensure a qualitative content analysis with a high reliability. First, the deductive approach was implemented with 
assorted literature on social media to get guidance for the research categories (see [19]). Additionally, the inductive approach via observation of live streams on the investigated three general SLSSs (YouNow, Periscope, and Ustream) was used to get a general idea on what people stream about (content categories), likewise the streamers were asked about their motives via the chat system of the service to get a first insight on this (motive categories). The categories and their responding sub-categories that resulted from this approach are:

Content. For the content of the stream, a tally chart was made. The different kinds of streaming content were: to chat; make music; share information; news; fitness; sport event; gaming; animals; entertainment media; spirituality; draw/paint a picture; 24/7; science, technology, and medicine (STM); comedy; advertisement; nothing; slice of life; politics; nature; food; business information; others.

Motivation. A tally chart was used for the motives of the streamer, which were: boredom, fun, hobby, to reach a specific group, exchange of views, socializing, loneliness, relationship management, need to communicate, need to belong, selfimprovement, self-expression, sense of mission, to become a celebrity, to make money, trolling. „No comment" was marked if the streamer did not state a motivation or no person could be reached via chat, for example if an animal was shown or a 24/7 stream (e.g. from a webcam) was broadcasted.

Norm entries were used for the formalities. Those were: gender (male, female, group, other); age of the streamer.

The data of the three general SLSSs (YouNow, Periscope, and Ustream) were collected from three different countries, namely Germany, Japan, and the United States of America. To ensure that the streams originated from those countries the declaration of the country for a broadcast on each platform was checked for every stream. Additionally, the data collectors had the required language skills for those countries. Twelve research teams consisting of two persons per team were formed. The teams were evenly distributed between the three countries. Every coder received a spread sheet and coded the data in it when any of the investigated aspects was applicable to the stream. For collecting the data, the 'four eyes principle,' or two-man rule was applied, which means that each stream was observed simultaneously but independently by two people for two to a maximum of ten minutes. This time span was chosen because we felt that it was sufficient enough for our purpose to gain understanding what the stream is about. The two observers communicated in order to guarantee a 100 percent intercoder agreement, which sometimes resulted in discussions, but a consensus could always be reached. Usually, the streams were observed in two phases. First, the stream was watched, and the data were collected. In phase two, if some aspects were not clear, for example the motivation of the streamer, the streamer was asked via the chat system of the service. In the end, a data set of a total of 7,667 different streams in a time span of four weeks, from April 26 to May 24, 2016, was collected.

\subsection{Statistical Procedure}

Former studies matched the selected motives with the Uses and Gratifications theory and our proposed model (information, entertainment, self-presentation, social interaction) [26], but without any statistical foundation. Now we are interested to see if our proposed motives can be clustered into groups and matched with the Uses and Gratifications theory. To answer RQ1, we want to identify homogenous groups of variables and to this end conducted an interdependence analysis. To do so we chose the hierarchical cluster method. This approach is agglomerative, which means that each object is in a cluster by its own at first and later, two objects are merged as a new cluster, resulting in one big cluster consisting of all objects. Since our variables are binary coded we chose the complete-linkage algorithm, or farthest neighbor clustering:

$$
D(X, Y)=\max _{x \in X, y \in Y} d(x, y) .
$$

$d(x, y)$ is the distance between elements $x \in X$ and $y \in Y$, and $X$ and $Y$ are two sets of elements or clusters. We wanted to avoid forcing elements together just because single elements are close to each other, even though the other elements in each cluster may be distant to each other and refrained from using the single-linkage method. Our aim was to find very homogenous groups and thus chose the completelinkage algorithm [43].

To calculate the similarity matrix, the Jaccard similarity coefficient, $J$, was used [44]:

$$
J=\frac{M_{11}}{M_{01}+M_{10}-M_{11}} .
$$

$M_{11}$ is the number of attributes were two objects have a value of $1, M_{01}$ is the number of attributes were the first object has a value of 1 and the other of $0, M_{10}$ is the number of attributes were the first object has a value of 0 and the other a value of 1 . The coefficient weighs the presence of the attribute as more important than as its non-presence, making it adequate for our investigation, since we want to 
group our variables based on the presence of the attribute, i.e. the motive of the streamer.

To investigate if the cluster has any reliability and internal consistency we used Cronbach's alpha, more precisely Kuder-Richardson-20 (KR20), since the variables are dichotomous:

$$
\rho_{K R 20}=\frac{k}{k-1}\left(1-\frac{\sum_{j=1}^{k} p_{j} q_{j}}{\sigma^{2}}\right) .
$$

$k$ means the number of questions, $p_{j}$ is the number of streamers answering with yes concerning a motive, $q_{j}$ were answered with no, $\sigma^{2}$ is the variance of the total scores of all streamers that were observed. The range lies between 0 and 1 , with a high value indicating reliability, but a value over .90 indicating a homogenous test [45].

A descriptive approach was used to answer RQ2 and RQ3, here, for the genders, generations and content categories, the percentage distribution for the four motives was calculated.

\section{Results}

\subsection{Demographics of SLSSs' users}

In our study (observation of streams; $\mathrm{N}=4,548$ streams with single broadcasters), we identified 61.2 percent male broadcasters and 38.8 percent females. The results from Tang, Venial and Inkpen [17, p. 4774] and Alexa confirm this distribution.

Following the results of researches on generational cohorts of social media users [46,47], there is the Silent Generation (born between 1925 and 1945), the Baby Boomers (1946 - 1960), Generation X (1961 - 1980), Generation Y (1981 1999) and Generation $Z$ (born after 2000). Whereas more than half of all YouNow streamers of our second study belong to the youngest generation $\mathrm{Z}$, just 4 percent of Ustream users belong to this group. Instead, about one quarter of all Ustream users are among the oldest generations (combined Silent Generation and Baby Boomers). Additionally, Ustream is applied mostly by Generation X. Periscope is mostly used by Generation Y. Here we have a clear result: There is no single pattern of generational cohorts using SLSSs; instead, the cohort distribution depends strongly on the specific service: YouNow has the youngest users (mostly Generation $\mathrm{Z}$, some Generation Y); Periscope is used by young adults (mostly Generation Y, some Generation Z and some Generation $\mathrm{X}$ ); finally, Ustream has the oldest users (Generation X, some Generation Y, some Silent Generation and Baby Boomers).

\subsection{Motivations of the streamers (RQ1)}

First, the results of our cluster analysis are discussed. To visualize the arrangement of the clusters, a dendrogram was calculated. The dendrogram shows clusters of compounds according to how strongly correlated the compounds are. Following the dendrogram, we split the cluster into four different groups:

- Group 1: need to communicate, exchange of views, relationship management, reaching a specific group, sense of mission;

- Group 2: hobby, fun, self-expression, becoming a celebrity, self-improvement, making money;

- Group 3: boredom, socializing, needing to belong, loneliness;

- Group 4: trolling.

When calculating the reliability score for all motives with the KR20 formula, we get a value of .544 , indicating a weakly reasonable reliability concerning the consistency of the stated motives [48]. The value implies that the grouping of the motives in four categories is sensible, but that people, in this case streamers, are diverse in their motives. For example, someone who streams out of boredom does not necessarily do it because he is seeking social interactions.

Our theoretical model proposes four different main motives, which are entertainment, social interaction, self-presentation, and information. Each cluster that was calculated represents one of these main motives.

Group 1 corresponds with information, since all aspects of it are concerned with either attaining (relationship management) or distributing (sense of mission, reaching a specific group) information, or both (need to communicate, exchange of views). Group 2 is concerned with self-presentation. Here we find people who want to express themselves, with a hobby or just by having fun. By becoming a celebrity and making money, this is the ideal way to present oneself. In Group 3 we find the streamers who yearn for social interaction, but also entertainment, they want to belong, and mask their loneliness and boredom. Group 4 is a special kind of users; they are the trolls.

Concerning the central motivations, group 3/social interaction (34.6 percent) is represented the most on SLSSs (Table 2), followed by group 2/selfpresentation (33.4 percent), group 1/information (30.3 percent) and, at the last place, the trolls (1.7 percent). When we take a closer look at the motives, many streamers are motivated by boredom (48.7 percent) and socializing (36.5 percent) and use 
SLSSs to satisfy their need for social interactions. Concerning self-presentation, streamers prefer to use SLSSs for fun (28.9 percent) and as their hobby (18.9 percent) rather than more serious motives like making money (13.4 percent) or self-improvement (6.9 percent).

Table 2. Streamers' motives on SLSSs

\begin{tabular}{lc}
\hline Motive & Relative Frequency \\
\hline Social Interaction & $34.6 \%$ \\
--- Boredom & $48.7 \%$ \\
--- Socializing & $36.5 \%$ \\
--- Need to Belong & $9.3 \%$ \\
--- Loneliness & $5.4 \%$ \\
\hline Self-Presentation & $33.4 \%$ \\
--- Fun & $28.9 \%$ \\
--- Self-expression & $23.6 \%$ \\
--- Hobby & $18.9 \%$ \\
--- Making Money & $13.4 \%$ \\
--- Becoming a Celebrity & $8.4 \%$ \\
--- Self improvement & $6.9 \%$ \\
\hline Information & $30.3 \%$ \\
--- Reaching a Group & $34.4 \%$ \\
--- Need to Communicate & $33.2 \%$ \\
--- Exchange of Views & $14.8 \%$ \\
--- Sense of Mission & $9.8 \%$ \\
--- Relationship Manag. & $8.0 \%$ \\
\hline Trolling & $1.7 \%$ \\
--- Trolling & $100.0 \%$ \\
\hline Streams on YouNow, Periscope and Ustream from \\
the U.S., Japan and Germany; in some cases \\
multiple assignments; N $7,667$. & \\
\hline
\end{tabular}

When attaining or receiving information is the focus of the streamers, most of them want to reach a group of people (34.4 percent). Others want to have a conversation on a topic (14.8 percent). Last, we find the trolls as a tiny minority on SLSSs (1.7 percent).

\subsection{Central motivations and content (RQ2)}

What content do the streamers produce on SLSSs? Looking at Table 3, we see that chatting (on diverse topics) is the main content category. 44.0 percent of all observed streams exhibit such action. This seems to be a stable result since Tang, Veniola and Inkpen [17, p. 4773] arrive at the same conclusion. Sharing information (of diverse topics), 24/7 (i.e., webcams), slice of life, and playing entertainment media are further frequently identified content categories. About 12 percent of all streams exhibit - nothing; no streamer available, and no action, just a silent and empty space.
The majority of the streams in the mentioned top six content categories requires only a minimum of cognitive effort [49].

Table 3. Content categories on SLSSs

\begin{tabular}{lc}
\hline Content & Relative Frequency \\
\hline Chatting & $44.0 \%$ \\
Share information & $17.2 \%$ \\
$24 / 7$ & $15.1 \%$ \\
Slice of life & $14.3 \%$ \\
Nothing & $12.3 \%$ \\
Entertainment media & $11.7 \%$ \\
Make music & $9.6 \%$ \\
Animals & $6.7 \%$ \\
Nature & $5.5 \%$ \\
Gaming & $5.5 \%$ \\
Sports & $3.9 \%$ \\
News & $3.4 \%$ \\
Spirituality & $3.1 \%$ \\
Advertising & $2.9 \%$ \\
Food & $2.3 \%$ \\
Comedy & $1.5 \%$ \\
Fitness & $1.4 \%$ \\
Politics & $1.4 \%$ \\
Business information & $1.4 \%$ \\
STM & $0.9 \%$ \\
Draw/Paint a picture & $0.8 \%$ \\
\hline Streams on YouNow, Periscope and Ustream from \\
the U.S., Japan and Germany; \\
multiple assignments; N $=7,667$ \\
\hline
\end{tabular}

In all other content categories, the streamer's cognitive effort is much higher. To make music (9.6 percent) presupposes that one can play an instrument; to talk about sports, politics, business or science, technology and medicine (STM) presumes some background in the knowledge domain. The news category underlines the importance of SLSSs in sharing breaking news [18].

However, in some content areas, of e.g. e-Sports and painting, with Twitch [13-16,30,41] and Picarto there are specialized SLSSs, which found their expert audience.

Up to today, there are very few studies on the interrelationships between motivations and usergenerated content. The following Tables 4-7 show the top 10 content categories of streams divided by central motivation of the respective streamer (social interaction, self-presentation, information, and trolling).

Table 4 presents the top content categories for streamers motivated by social interaction. The streamers display a high number of streams where they just chat with the viewer (77.5 percent). 
Table 4. Top content categories of streamers motivated by social interaction

\begin{tabular}{|c|c|}
\hline \begin{tabular}{l|l} 
Content & Social Interaction
\end{tabular} & Relative Freq. \\
\hline 1. Chatting & $77.5 \%$ \\
\hline 2. Share Information & $22.3 \%$ \\
\hline 3. Slice of Life & $18.5 \%$ \\
\hline 4. Nothing & $13.9 \%$ \\
\hline 5. Entertainment Media & $9.0 \%$ \\
\hline 6. Make Music & $7.7 \%$ \\
\hline 7. Food & $3.4 \%$ \\
\hline 8. $24 / 7$ & $3.4 \%$ \\
\hline 9. Gaming & $2.9 \%$ \\
\hline 10. Advertising & $2.2 \%$ \\
\hline
\end{tabular}

With an occurrence that is a lot lower, we find sharing information (22.3 percent) and sharing the streamer's every-day life (18.5 percent). Streams on gaming (5.5 percent) and on drawing a picture (0.8 percent) are scarce on YouNow, Periscope, and Ustream.

Table 5. Top content categories of streamers motivated by self-presentation

\begin{tabular}{|c|c|}
\hline \begin{tabular}{|l|l|} 
Content & Self-Presentation
\end{tabular} & Relative Freq. \\
\hline 1. Chatting & $55.0 \%$ \\
\hline 2. Share Information & $22.5 \%$ \\
\hline 3. Entertainment Media & $16.7 \%$ \\
\hline 4. Make Music & $16.0 \%$ \\
\hline 5. Slice of Life & $15.2 \%$ \\
\hline 6. Nothing & $7.5 \%$ \\
\hline 7. $24 / 7$ & $7.2 \%$ \\
\hline 8. Gaming & $6.9 \%$ \\
\hline 9. Sports & $4.7 \%$ \\
\hline 10. Advertising & $4.6 \%$ \\
\hline
\end{tabular}

The top content categories of streamers motivated by self-presentation are presented in Table 5 . Here, contrary to the distribution among the social interaction group, we find entertainment media on the $3^{\text {rd }}$ place (16.7 percent). As the main content we find chatting (55.0 percent) and sharing information (22.5 percent). Gaming is also represented more (6.9 percent).

Table 6 presents the content categories of streamers motivated by information. If the streamers are motivated by information, they are eager chat (44.2 percent) and share information (31.2 percent) with the viewer. We also find content categories which are potentially informative to the viewer, for example the sharing of news (6.8 percent), speaking about spirituality (6.9 percent), or showing/talking about animals (7.4 percent).
Table 6. Top content categories of streamers motivated by information

\begin{tabular}{|c|c|}
\hline \begin{tabular}{l|l} 
Content & Information
\end{tabular} & Relative Freq. \\
\hline 1. Chatting & $44.2 \%$ \\
\hline 2. Share Information & $31.2 \%$ \\
\hline 3. Entertainment Media & $14.3 \%$ \\
\hline 4. $24 / 7$ & $14.2 \%$ \\
\hline 5. Slice of Life & $13.3 \%$ \\
\hline 6. Make Music & $9.9 \%$ \\
\hline 7. Nothing & $9.1 \%$ \\
\hline 8. Animals & $7.4 \%$ \\
\hline 9. Spirituality & $6.9 \%$ \\
\hline 10. News & $6.8 \%$ \\
\hline
\end{tabular}

Table 7 shows the last main motivation category, namely "trolling." If the streamers want to troll their viewers, they do so by chatting (52.3 percent), or displaying nothing (44.2 percent). We also find entertainment media (19.8 percent) and in contrast to the other motivations, streams containing comedic content (18.6 percent).

Table 7. Top content categories of streamers motivated by trolling

\begin{tabular}{|c|c|}
\hline \begin{tabular}{l|l} 
Content & Trolling
\end{tabular} & Relative Freq. \\
\hline 1. Chatting & $52.3 \%$ \\
\hline 2. Nothing & $44.2 \%$ \\
\hline 3. Share Information & $22.1 \%$ \\
\hline 4. Entertainment Media & $19.8 \%$ \\
\hline 5. Comedy & $18.6 \%$ \\
\hline 6. $24 / 7$ & $17.4 \%$ \\
\hline 7. Slice of Life & $12.8 \%$ \\
\hline 8. Make Music & $8.1 \%$ \\
\hline 9. Advertising & $7.0 \%$ \\
\hline 10. Food & $5.8 \%$ \\
\hline
\end{tabular}

\subsection{Gender-dependent and generational- dependent differences in central motivation (RQ 3)}

Finally, we look at gender-dependent and generational differences in central motivations. During the observation, we categorized the streamers as "female," "male," or "group" (when two or more people were in the stream). The generations were split into Generation Z, Generation Y, Generation X, Baby Boomers, and the Silent Generation. Since only two cases for the Silent Generation was registered if motivations were stated, they are not included in this analysis.

Regarding the central motives of the genders and groups (Table 8), there were no significant 
differences for the self-presentation category. But we find moderately high differences if social interactions are concerned. Female streamers are mostly motivated by social interactions (55.3 percent), followed by men (44.1 percent), and lastly, by groups (35.7 percent). Since groups are already in a social setting, this could explain the relatively small percentage for the desire to interact with others via a live stream because of social reasons.

If information as the main motive is concerned, we find that groups are the most interested in it (38.7 percent), followed by male streamers (31.9 percent) and lastly female streamers (28.7 percent). Male streamers are comparatively more interested in trolling (1.8 percent) than female streamers (1.2 percent) or groups (1.0 percent).

\section{Table 8. Gender-dependent differences in} central motives

\begin{tabular}{lllc}
\hline Motive & Male & Female & Group \\
\hline Social Interaction & $44.1 \%$ & $55.3 \%$ & $35.7 \%$ \\
Self-presentation & $39.1 \%$ & $35.2 \%$ & $39.4 \%$ \\
Information & $31.9 \%$ & $28.7 \%$ & $38.7 \%$ \\
Trolling & $1.8 \%$ & $1.2 \%$ & $1.0 \%$ \\
\hline Male N=2,782; female $\mathrm{N}=1,766$, & group=1,082; \\
\multicolumn{4}{l}{ sometimes multiple assignments } \\
\hline
\end{tabular}

Looking at the generational-dependent differences, we can observe some differences (Table 9). Generation $\mathrm{Z}$ is highly motivated by social interactions (61.7 percent) as is Generation Y (45.7 percent). The percentages decline further with Generation X (31.0 percent) and the Baby Boomers (6.5 percent). If self-presentation is concerned, we find that Generation $\mathrm{Z}$ is comparatively higher motivated by it (43.7\%) than Generation Y (35.9 percent), Generation X (36.5 percent), and the Baby Boomers (35.5 percent).

Table 9. Generational-dependent differences in central motives

\begin{tabular}{|c|c|c|c|c|}
\hline Motive & Gen Z & Gen Y & Gen X & $\mathrm{BB}$ \\
\hline Social Interaction & $61.7 \%$ & $45.7 \%$ & $31.0 \%$ & $6.5 \%$ \\
\hline Self-presentation & $43.7 \%$ & $35.9 \%$ & $36.5 \%$ & $35.5 \%$ \\
\hline Information & $27.2 \%$ & $29.7 \%$ & $50.3 \%$ & $64.5 \%$ \\
\hline Trolling & $1.6 \%$ & $1.9 \%$ & $0.6 \%$ & $0 \%$ \\
\hline $\begin{array}{l}\text { Gen Z N=1,839; } \\
\text { Boomers (BB) } \\
\text { assignments }\end{array}$ & $\begin{array}{l}\mathrm{YN}= \\
\mathrm{N}=31\end{array}$ & $\begin{array}{l}70 ; \mathrm{G} \\
\text { som }\end{array}$ & $\begin{array}{l}\mathrm{XN}=4 \\
\text { nes }\end{array}$ & $\begin{array}{l}\text { 3; Baby } \\
\text { ultiples }\end{array}$ \\
\hline
\end{tabular}

Only 27.2 percent of Generation $\mathrm{Z}$ and 29.7 percent by Generation $\mathrm{Y}$ are motivated by information, but 50.3 percent of Generation $\mathrm{X}$ and 64.5 percent of the Baby Boomers. Concerning the trolls on SLSSs, we find the highest percentage with Generation Y (1.9 percent) and not one instance with the Baby Boomers.

For the genders we could observe that women and men are highly motivated by social interactions. Groups tend to be motivated by information but also self-presentation. Looking at what motivates different generations to use SLSSs, we can see a clear shift with maturing age. While the younger users prefer social interactions on SLSSs, the older generations are more interested in information.

\section{Conclusion}

In order to study and to understand user behavior on SLSSs, we applied log-file analysis (however, by referring to Alexa, only indirectly), and systematic observations of more than 7,600 live online videos on YouNow, Periscope, and Ustream produced by streamers from the US, Japan, and Germany.

Concerning the demographics, there are clear results: about three fifths of the users are male and correspondingly only two fifths are female. There is no unique pattern of using SLSSs by generational cohorts; instead, different services address different age groups (YouNow mostly Generation Z, Periscope Generation Y, and Ustream Generation X and older people).

We often found content categories (chatting and sharing diverse information; 24/7, slice of life, nothing, playing entertainment media), which do not call for cognitive effort, neither of the streamers nor of the viewers. However, about 10 percent of all broadcasts show streamers making music. Niche topics with high amounts of cognitive effort as politics or STM find their interested viewers and participants. 3.4 percent of all live streams address news, which is an indicator for the importance of SLSSs for sharing breaking news.

(RQ1) The four central motives in the sense of Uses and Gratification Theory are uneven distributed; most frequent is social interaction followed by selfpresentation, information, and trolling. Concerning single motives, the top need is the satisfaction of the streamers' boredom.

(RQ2) When considering the interrelation between the central motives and the content categories, there are a few considerable differences between the groups. Chatting and sharing information were the top content categories for three of the central motives (social interaction, self-presentation, information).

Every motivation category has a content category that was not in the top ten ranking for the other three motives. For social interaction, we find food related 
content. Here, we often saw people eating in restaurants, who potentially needed some form of social interaction when eating alone. If the streamers wanted to present themselves, the broadcasted sports related content. If the obtaining or distribution of information is considered, we find streams with animal related content, and also people talking about spirituality. Trolls who want to entertain themselves do so by using comedy.

"Nothing" as content category was given for all central motives. Its share was the highest for the entertainment category (44.2 percent) and lowest for self-presentation (7.5 percent).

The highest share of streams in the "making music" content category was given for the streamers motivated by self-presentation and - to a very high degree - for those who want to become a microcelebrity [25].

(RQ3) When considering gender-dependent and generational-dependent differences, a few distinct differences could be observed. First, female streamers are more concerned with social interactions on SLSSs than male streamers or groups. For selfpresentation, we could observe that male streamers and groups are slightly more interested in it than female streamers, whereas groups are more interested in obtaining or sharing information with others than male or female streamers. For the trolls on SLSSs, we found males with the highest percentages.

Looking at the generations and their motivations, we were able to recognize some trends as well. Younger streamers, precisely, Generation Z, and Generation $\mathrm{Y}$ are interested in social interactions and self-presentation, with a much higher percentage than more mature streamers from Generation $\mathrm{X}$ and the Baby Boomers. For the Baby Boomers we only found 6.5 percent of people that want to use SLSSs because of socially motivated reasons. The older streamers seem to be more interested in obtaining or sharing information than the younger streamers. The trolls were mainly found in the younger user groups, implying that older streamer are more mature when their motivations are concerned.

\section{Limitations and outlook}

This study has limitations. As seen in Table 1, there are several SLSSs; however, we studied only three of them. If we could include the Japanese niconico and the Chinese SLSSs, since there are more than 200 SLSSs in China [50], it becomes possible to strengthen our understanding on cultural environments of SLSSs. Likewise, we did not analyze topic-related SLSSs as Picarto or Twitch. As there are studies on gratification and motivation on
Twitch [15,30,51,52] it would be interesting to compare the findings of topic-related SLSSs with those of general SLSSs.

General SLSSs (as YouNow, Periscope and Ustream) and specialized SLSSs (as Picarto and Twitch) are synchronous SNSs. There is a vast amount research on asynchronous SNSs [e.g., 53] (especially, on Facebook [e.g., 54,55]). What are the similarities and what the differences of the users' information behavior on both types of SNSs?

An aspect often discussed in information behavior research is the information seeking behavior of users, which we passed over. Unlike in the world of TV, on SLSSs there are no program guides. However, there are multiple ways to search for live videos, e.g. by (however, very broad) hashtags as “\#dance," by locations on a world map (on Periscope), by entries on a user's homepage on an SLSS (if there are fixed broadcasting times) or by posts of the broadcaster on Twitter or Instagram, for instance. Besides a short notice on searching with hashtags on YouNow [20, p. 22], there is no empirical study on information seeking behavior on SLSSs, which is a serious research gap.

Social Live Streaming Services are a newly established form of Social Networking Services and of Live-TV. In terms of scientific research, communication research meets social media research when analyzing live videos on SLSSs.

As all information production, participation as well as information reception behavior happens in real-time, SLSSs are an exciting and promising new research field in TV research as well as in social media studies.

\section{References}

[1] P. Stewart, The live-streaming handbook, Routledge, Abington, Oxon, UK, 2016.

[2] K. Scheibe, K.J. Fietkiewicz, and W.G. Stock, "Information behavior on social live streaming services", Journal of Information Science Theory and Practice, 4(2), 2016, pp. 6-20.

[3] R. Maugeri, R.G. Giammalva, and D.G. Iacopino, “On the shoulders of giants, with a smartphone: Periscope in neurosurgery”, World Neurosurgery, 92, 2016, pp. 569570 .

[4] C.T. Dowell, and D.F. Duncan, "Periscoping economics through someone else's eyes: A real world (Twitter) app”, International Journal of Economic Education, 23, 2017, pp. 34-39.

[5] K. Keinänen, "The role of live streaming in marketing communications and corporate branding”, Master's Thesis, Lappeenranta University of Technology, LUT School of Business and Management, Lappeenranta, Finland. 
[6] A. Ainslie. "The burden of protecting live sports telecasts: The real time problem of live streaming and appbased technology”, Southwestern Law School, Los Angeles, CA, 2015.

[7] C. Faklaris, F. Cafaro, S.A. Hook, A. Blevins, M. O'Haver, and N. Singhal, "Legal and ethical implications of mobile live-streaming video apps", in Proceedings of the 18th International Conference on Human-Computer Interaction with Mobile Devices and Services (September 6-9), ACM, New York, 2016, pp. 722-729.

[8] A. Honka, N. Frommelius, A. Mehlem, J.-N. Tolles, and K.J. Fietkiewicz, "How safe is YouNow? An empirical study on possible law infringements in Germany and the United States”, Journal of MacroTrends in Social Sciences, 1(1), 2015, pp. 1-17.

[9] F. Zimmer, K.J. Fietkiewicz, and W.G. Stock, "Law infringements in social live streaming services", in Proceedings of the HCI International 2017 Conference on Human Computer Interaction, Springer, Cham, Switzerland, 2017, pp. 567-585.

[10] D. Alamiri, and J. Blustein, "Privacy awareness and design for live video broadcasting apps," in Proceedings of the HCI International 2016 Conference on Human Computer Interaction, Springer International, Cham, Switzerland, 2016, pp. 459-464.

[11] P. Lessel, M. Mauderer, C. Wolff, and A. Krüger, "Let's play my way: Investigating audience influence in user-generated gaming live-streams", in Proceedings of the 2017 ACM International Conference on Interactive Experiences for TV and Online Video, ACM, New York, NY, 2017, pp. 51-63.

[12] P. Lessel, A. Vielhauer, and A. Krüger, "Expanding video game live-streams with enhanced communication channels: A case study", in Proceedings of the 2017 CHI Conference on Human Factors in Computing Systems, ACM, New York, NY, 2017, pp. 1571-1576.

[13] W.A. Hamilton, O. Garretson, and A. Kerne, "Streaming on Twitch: Fostering participatory communities of play within live mixed media", in Proceedings of the 2014 SIGCHI Conference on Human Factors in Computing Systems, ACM, New York, NY, 2014, pp. 1315-1324.

[14] Gros, D., Hackenholt, A., Zawadzki, P., and Wanner, B. "Interactions of Twitch users and their usage behavior", in Proceedings of the HCI International 2018 Conference on Human Computer Interaction, Springer International, Cham, Switzerland, 2018, pp. 201-213.

[15] Gros, D., Wanner, B., Hackenholt, A., Zawadzki, P., and Knautz, K., "World of Streaming, Motivation and Gratification on Twitch", in Proceedings of the HCI International 2017 Conference on Human Computer Interaction, Springer International, Cham, Switzerland, 2017, pp.44-57.

[16] R. Scully-Blaker, J. Begy, M. Consalvo, and S.C. Ganzon, "Playing along and playing for on Twitch: Livestreaming from tandem play to performance", in Proceedings of the 50th Hawaii International Conference on System Sciences, IEEE, Washington DC, 2017, pp. 2026-2035.

[17] J.C. Tang, G. Veniola, and K.M. Inkpen, "Meerkat and Periscope: I stream, you stream, apps stream for live streams”, in Proceedings of the 2016 CHI Conference on
Human Factors in Computing Systems, ACM, New York, NY, 2016, pp. 4770-4780.

[18] J.C. Tang, F. Kivran-Swaine, K. Inkpen, and N. Van House, "Perspectives on live streaming: Apps, users, and research", in Proceedings of the 18th ACM Conference Companion on Computer Supported Cooperative Work \& Social Computing, ACM, New York, NY, 2017, pp. 123126.

[19] M.B. Friedländer, "Streamer motives and usergenerated content on social live-streaming services", Journal of Information Science Theory and Practice, 5(1), 2017, pp. 65-84.

[20] M.B. Friedländer, “And action! Live in front of the camera: An evaluation of the social live streaming service YouNow", International Journal of Information Communication Technologies and Human Development, 9(1), 2017, pp. 15-33.

[21] K.J. Fietkiewicz, and K. Scheibe, "Good morning ... good afternoon, good evening and good night: Adoption, usage and impact of the live streaming platform YouNow", in 3rd Intern Conference on Library and Information Science (LIS 2017), International Business Academics Consortium, Taiwan, 2017, pp. 92-115.

[22] T. Kasakowskij, "Does age influence the way people interact with social live streaming services?”, in Proceedings of the HCI International Conference 2018 on Human Computer Interaction, Springer International, Cham, Switzerland, 2018, pp. 214-228.

[23] F. Zimmer, "A content analysis of social live streaming services", in Proceedings of the HCI International Conference 2018 on Human Computer Interaction, Springer International, Cham, Switzerland, 2018, pp. 400-414.

[24] K. Scheibe, "The impact of gamification in social live streaming services”, in Proceedings of the HCI Conference International 2018 on Human Computer Interaction, Springer International, Cham, Switzerland, 2018, pp. 99113.

[25] K.J. Fietkiewicz, I. Dorsch, K. Scheibe, F. Zimmer, K. Scheibe, and W. G. Stock, "Dreaming of stardom and money: Micro-celebrities and influencers on live streaming services", in Proceedings of the HCI International 2018 Conference on Human Computer Interaction, Springer International, Cham, Switzerland, 2018, pp. 240-253.

[26] K. Scheibe, F. Zimmer, and K.J. Fietkiewicz, „Das Informationsverhalten von Streamern und Zuschauern bei Social Live-Streaming Diensten am Fallbeispiel YouNow“, Information - Wissenschaft \& Praxis, 68(5-6), 2018, pp. 352-364.

[27] P.-S. Hsieh, J. Ou, and J. Xu, "Will you "tip” celebrated streamers? Sense of virtual community and the moderating role of subjective happiness", in Proceedings of the 51st Hawaii International Conference on System Sciences, IEEE, Washington, DC, 2018, pp. 2110-2119.

[28] P.R. Todd, and J. Melancon, "Gender and livestreaming: source credibility and motivation”, Journal of Research in Interactive Marketing, 12(1), 2017, pp. 79-93.

[29] C.-C. Chen, and Y.-C. Lin, "What drives live-stream usage intention? The perspectives of flow, entertainment, social interaction, and endorsement”, Telematics and Informatics, 35, 2018, pp. 293-303. 
[30] Q. Zhao, C.-D. Chen, H.-W. Cheng, and J.-L. Wang, "Determinants of live streamers' continuance broadcasting intentions on Twitch: A self-determination theory perspective", Telematics and Informatics, 35, 2018, pp. 406-420.

[31] Blumler, J.G., and E. Katz, The uses of mass communications: Current perspectives on gratifications research, Sage, Newbury Park, CA, 1974.

[32] McQuail, D., Mass communication theory, Sage, London, UK, 1983.

[33] F. Zimmer, K. Scheibe, and W.G. Stock, “A model for information behavior research on social live streaming services (SLSSs)", in Proceedings of the $20^{\text {th }} \mathrm{HCI}$ International Conference on Human Computer Interaction, Springer International, Cham, Switzerland, 2018, pp. 429448.

[34] G. Shao, "Understanding the appeal of user-generated media: A uses and gratification perspective”, Internet Research, 19(1), 2009, pp. 7-25.

[35] K. Scheibe, C. Meschede, J. Göretz, and W.G. Stock W.G., "Giving and taking gratifications in a gamified social live streaming service", in Proceedings of the 5th European Conference on Social Media, Academic Conferences and Publishing Limited, Reading, UK, 2018, pp. 264-273.

[36] D. Stohr, T. Li, S. Wilk, S. Santini, and W. Effelsberg, "An analysis of the YouNow live streaming platform", in 40th Local Computer Networks Conference Workshops, IEEE, Washington, DC, 2015, pp. 673-679.

[37] L.S.L. Lai, and W.M. To, "Content analysis of social media: A grounded theory approach”, Electronic Commerce Research and Applications, 16(2), 2015, pp. 138-152.

[38] K.J. Fietkiewicz, E. Lins, K.S. Baran, and W.G. Stock, "Inter-generational comparison of social media use: Investigating the online behavior of different generational cohorts", in Proceedings of the 49th Hawaii International Conference of System Sciences, IEEE, Washington, DC, 2016, pp. 3829-3838.

[39] K.J. Fietkiewicz, E. Lins, and A. Budree, "Investigating the generation- and gender-dependent differences in Social Media use: A cross-cultural study in Germany, Poland and South Africa”, in Proceedings of the $20^{\text {th }}$ HCI International Conference on Human Computer Interaction, Springer International, Cham, Switzerland, 2018, pp.183-200).

[40] Krippendorff, K., Content analysis: An introduction to its methodology (3rd ed.), Sage, Thousand Oaks, CA, 2012. [41] D. Recktenwald, "Toward a transcription and analysis of live streaming on Twitch”, Journal of Pragmatics, 115, 2017, pp. 68-81.

[42] S. Elo, and S. H. Kynga, "The qualitative content analysis process", Journal of Advanced Nursing, 62(1), 2008, pp. 107-115.

[43] Aldenderfer, M.S., and R.K. Blashfield, Cluster analysis, Sage Publications, Newbury Park, 1984.

[44] Jaccard, P., "Distribution de la flore alpine dans le bassin des Dranses et dans quelques régions voisines", Bulletin de la Société Vaudoise des Sciences Naturelles, 37, 1901, pp. 241-272.
[45] Kuder, G.F., and M.W. Richardson, "The theory of the estimation of test reliability”, Psychometrika, 2(3), 1937, pp. 151-160.

[46] K.J. Fietkiewicz, E. Lins, K.S. Baran, and W.G. Stock, "Inter-generational comparison of social media use: Investigating the online behavior of different generational cohorts", in Proceedings of the 49th Hawaii International Conference of System Sciences, IEEE, Washington, DC, 2016, pp. 3829-3838.

[47] L. Leung, "Generational differences in content generation in social media: The roles of the gratifications sought and of narcissism”, Computers in Human Behavior, 29, 2013, pp. 997-1006.

[48] Mohamad, M.M., Sulaiman, N.L., Sern, L.C., and Salleh, K.M., "Measuring the validity and reliability of research instruments", Procedia - Social and Behavioral Sciences, 204, 2015, pp. 164-171.

[49] S.W. Tyler, P.T. Hertel, M.C. McCallum, and H.C. Ellis, "Cognitive effort and memory", Journal of Experimental Psychology: Human Learning and Memory, 5(6), 1979, pp. 607-617.

[50] Z. Lu, H. Xia, S. Heo, and D. Wigor, "You watch, you give, and you engage: A study of live streaming pratices in China”, in Proceedings of the 2018 CHI Conference on Human Factors in Computing Systems, ACM, New York, 2018, pp. 1-13.

[51] M. Sjöblom, M. Törhönen, J. Hamari, and J. Macey, "Content structure is king: An empirical study on gratifications, game genres and content type on Twitch", Computers in Human Behavior, 73, 2017, pp. 161-171.

[52] M. Sjöblom, and J. Hamari, "Why do people watch others play video games? An empirical study on the motivations of Twitch users", Computers in Human Behavior, 75, 2017, pp. 985-996.

[53] P.B. Brandtzæg, and J. Heim, "Why people use Social Networking Sites", in Online communities and social computing, A.A. Ozok, and P. Zaphiris (eds.), Springer, Berlin, Germany, 2009, pp. 143-152.

[54] K. Knautz, and K.S. Baran (eds.), Facets of Facebook. Use and users, De Gruyter, Berlin, Germany, Boston, MA, 2016.

[55] K.S. Baran, and H. Ghaffari, "The manifold research fields of Facebook: A bibliometric analysis", Journal of Information Science Theory and Practice, 5(2), 2017, pp. 33-47. 